\title{
Magnetic resonance-guided interstitial high-intensity focused ultrasound for brain tumor ablation
}

\author{
Jacquelyn MacDonell, MS, ${ }^{1,2}$ Niravkumar Patel, PhD, ${ }^{3}$ Sebastian Rubino, MD, ${ }^{1,2}$ \\ Goutam Ghoshal, PhD, ${ }^{4}$ Gregory Fischer, PhD, ${ }^{3}$ E. Clif Burdette, PhD, ${ }^{4}$ Roy Hwang, MD, ${ }^{1}$ and \\ Julie G. Pilitsis, MD, PhD ${ }^{1,2}$
}

\begin{abstract}
Departments of ${ }^{1}$ Neuroscience and Experimental Therapeutics and ${ }^{2}$ Neurosurgery, Albany Medical Center, Albany, New York; ${ }^{3}$ Robotics Engineering Program, Worcester Polytechnic Institute, Worcester, Massachusetts; and ${ }^{4}$ Acoustic MedSystems, Inc., Savoy, Illinois
\end{abstract}

\begin{abstract}
Currently, treatment of brain tumors is limited to resection, chemotherapy, and radiotherapy. Thermal ablation has been recently explored. High-intensity focused ultrasound (HIFU) is being explored as an alternative. Specifically, the authors propose delivering HIFU internally to the tumor with an MRI-guided robotic assistant (MRgRA). The advantage of the authors' interstitial device over external MRI-guided HIFU (MRgHIFU) is that it allows for conformal, precise ablation and concurrent tissue sampling. The authors describe their workflow for MRgRA HIFU delivery.
\end{abstract}

https://thejns.org/doi/abs/10.3171/2017.11.FOCUS17613

KEY WORDS brain tumor; high-intensity focused ultrasound; neural ablation; MRI guided

$\mathrm{T}$ HE main goal of treatment of intracranial neoplasms is to eradicate tumor cells with minimal disruption of surrounding normal parenchyma. Stereotactic radiosurgery (SRS) has been used as one modality of treatment in appropriate cases. SRS is limited by the dose a patient can tolerate and adverse effects of radiation. These limitations provide a niche for alternative therapies. Furthermore, tissue samples cannot be obtained during treatment. Recently, thermal therapies including high-intensity focused ultrasound (HIFU) and laser interstitial thermal therapy (LITT) have been proposed as alternatives ${ }^{20} \mathrm{HIFU}$ has advanced significantly over the past several years, and with the advent of MRI-guided HIFU (MRgHIFU), noninvasive ablation is now possible. However, difficulties with penetration of the calvaria limit the use of HIFU in cases of superficial lesions. Additionally, ablation zones cannot be conformed to the tumor shape, and there is no ability to acquire tissue samples. In the present article, we propose a system that utilizes an intraparenchymal catheter to deliver HIFU therapy to treat intracranial neoplasms, and we describe the workflow as it relates to our swine model. We deliver HIFU through an MRI-guided robotic assistant (MRgRA) to improve efficiency and ergonomic issues.

\section{Role of Thermal Energy in Brain Tumor Ablation}

The treatment of brain metastasis is highly individualized based on tumor presentation. Factors such as tumor histology, size, and location relative to eloquent brain regions will determine what treatment options are available to patients. Currently, the standard of care for brain metastasis is limited to SRS, whole brain radiation therapy, and surgical resection. ${ }^{9,22,28}$ Each of these methods has limitations that result in debilitating side effects or disqualifies patients from treatment altogether.

Resection is generally only offered to patients with a single metastatic lesion that presents in noneloquent regions. Whole-brain radiation therapy is typically used in conjunction with other surgical therapies, and while it significantly reduces recurrence rates, it is accompanied by debilitating side effects such as radiation necrosis and leukoencephalopathy. ${ }^{4}$ Although SRS attempts to reduce

ABBREVIATIONS DOF = degrees of freedom; GBM = glioblastoma; HIFU = high-intensity focused ultrasound; LITT = laser interstitial thermal therapy; MRgHIFU = MRIguided HIFU; MRgRA = MRI-guided robot assistant; MRIT = MRI thermometry; SRS = stereotactic radiosurgery.

SUBMITTED September 29, 2017. ACCEPTED November 27, 2017.

INCLUDE WHEN CITING DOI: 10.3171/2017.11.FOCUS17613. 
radiation toxicity by targeting the metastases and avoiding surrounding tissue, $84 \%$ of patients will present with leukoencephalopathy within 4 years. ${ }^{2}$ Thermal ablative alternatives have been successfully applied to neurosurgical therapies, with HIFU used for the treatment of essential tremor and LITT for the treatment of epilepsy. ${ }^{3,7}$ Both require MRI thermometry (MRIT). These two therapies require the same workflow, but the mechanism behind which the thermal energy is generated differs, as does the distribution of energy.

MRI-guided LITT was first approved as an ablation therapy for intracranial lesions by the United States Food and Drug Administration in 2007, when it was initially used in the treatment of small brain tumors. ${ }^{13}$ Most applications are for focally contained, surgically inaccessible lesions, with some accessible lesions being treated as well. The benefit of LITT over conventional surgical removal is reduced healing time to expedite time to adjuvant chemotherapy and radiation therapy. The physics of LITT are based on light absorption causing the release of thermal energy from a low-voltage laser; this thermal energy raises the temperature to $60^{\circ} \mathrm{C}$, resulting in liquefactive necrosis. The characteristics of tumor versus normal parenchyma produce a demarcation in tissue absorption and therefore a steep temperature fall off in normal parenchyma. As a modality of treatment, studies suggest improved survival in patients with recurrent glioblastoma (GBM) and mixed results in those with metastatic brain tumors. ${ }^{21}$ Overall complications range from $20 \%-50 \%$, with a major complication rate of $<5 \%$. LITT cannot be used in the vicinity of great vessels, or large hemorrhages. ${ }^{20,21}$

HIFU was first used in the treatment of brain tumors during the late 1960 s and early 1970 s. $^{7}$ Since that time, modern HIFU treatment systems have evolved to include thermal ablation, intraprocedural anatomy- and temperature-sensitive MRI guidance, and the use of ultrasound phased arrays to correct for cranial distortion. ${ }^{11}$ The Insightec MRI-guided HIFU (MRgHIFU) unit, ExAblate 3000, was one of the first to include all 3 of these features and was used for primate feasibility studies in 2006. ${ }^{9}$ In 2008, McDannold et al. published the first case report in which they described the clinical application of MRgHIFU in 3 patients with GBM; they indicated how multiple focused ultrasound exposures were applied up to the maximum acoustic power available at the time. ${ }^{18}$ This was the first time a therapeutic ultrasound beam was focused in the human brain through an intact skull, but sufficient power was not available to achieve thermal coagulation of the brain tissue (achieved at temperatures of $55^{\circ} \mathrm{C}$ or greater). Finally, in 2014, Coluccia et al. reported the use of MRgHIFU to achieve tumor ablation without inducing neurological deficits or other adverse effects in a patient with recurrent GBM. ${ }^{5}$ Transmission of light energy in LITT results in charred tissue, creating a barrier in cases of large tumors, a characteristic not shared with HIFU. ${ }^{21}$

Until now, the use of MRgHIFU has been limited to case reports ranging from 1 to 3 people. The most recent clinical trial (NCT01473485; clinicaltrials.gov) seeking to evaluate the safety and feasibility of transcranial MRIguided focused ultrasound in the treatment of brain tu- mors is estimated to close in December 2017. Results will hopefully be available in 2018. Provided the safety and efficacy are similar to those shown in the initial case reports, the next steps will entail illustrating survival benefit of MRgHIFU both as a primary therapy in patients with nonresectable lesions and as an adjuvant therapy in those with resectable lesions.

HIFU has also been used in other areas of oncology, including palliation in patients with bone metastases and in the treatment of benign bone tumors, osteoid osteomas, breast cancer, liver cancer, kidney cancer, bladder cancer, and pancreatic cancer. ${ }^{10,15}$ Pancreatic cancer is the fourth leading cause of cancer deaths in the United States; approximately 53,670 Americans are projected to develop the disease in 2017 (https://seer.cancer.gov/csr/1975_2014/). More than $80 \%$ of pancreatic cancer presents as advanced unresectable disease, and the standard treatment options, including chemotherapy, radiotherapy, or both, only achieve a 6- to 12 -month survival benefit. ${ }^{12}$ HIFU ablation has been used as both a primary and a palliative treatment, with initial studies implying survival benefit over supportive care. ${ }^{14,17}$ Currently, HIFU treatment of pancreatic cancer is widely available in China, with limited availability in South Korea and Europe. ${ }^{12}$ Sofuni et al. evaluated the therapeutic effect of adding HIFU to current chemotherapy/chemoradiotherapy treatment algorithms in 120 patients with locally advanced and metastatic, unresectable pancreatic cancer being treated at Tokyo Medical University. The median survival period after diagnosis in the HIFU plus chemotherapy group was 997.8 days compared with 366.6 days in the chemotherapy-alone group and 582.7 days in the HIFU-alone group. ${ }^{26}$ In the latest phase 3 clinical trial in the United States randomly assigning patients to nab-paclitaxel plus gemcitabine (431 patients) or gemcitabine alone (430 patients), the median overall survival durations were only 263.5 and 207.7 days, respectively. ${ }^{27}$ In prostate cancer, similar HIFU technology has been proposed and used after radiation failure and in conjunction with resection..$^{19}$ In 2004, Diederich et al. presented a feasibility study of transurethral ultrasound applicators in canine prostates using MRIT. ${ }^{6}$ In this technology, a balloon catheter encapsulates the transducer to provide coupling and cooling of the urethra and adjacent tissue. The heating pattern can effectively deliver a $180^{\circ}$ arch with the ability to control thermal dose, angles, and radius. The initial data related to this therapy demonstrating increased survival in patients with pancreatic and prostate cancer are very promising and our robotically assisted delivery of HIFU is in clinical trials currently.

\section{Interstitial HIFU}

Although neurosurgical indications for HIFU have focused on extracorporeal devices such as transcranial MRgHIFU, intracavitary interstitial HIFU (also known as catheter-based HIFU) possibilities also are being explored by our laboratory and others in the preclinical setting (Fig. 1). HIFU ablation requires sequential coagulation of small overlapping volumes with multiple, individual, short-time, high-power sonications that cumulatively can cause treatment to last several hours. ${ }^{23}$ Treatment may be limited 


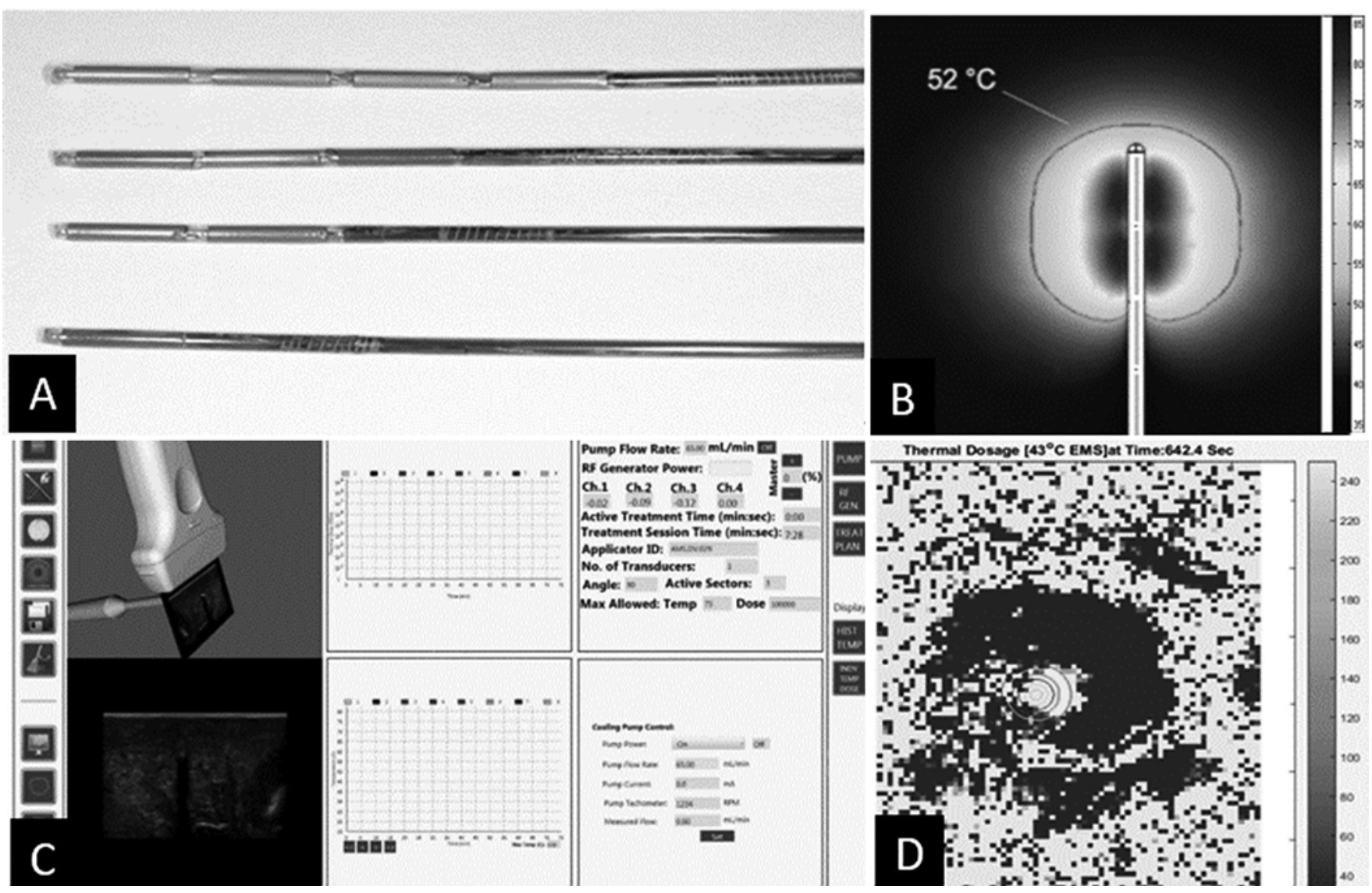

FIG. 1. Interstitial HIFU utilizes probes that can have multiple transducers in a linear array, allowing for conformal ablation. A: Four probes lined up each with an increasing number of transducers. B: Simulated ablative pattern for $360^{\circ}$ transducer scale showing degrees in Celsius. C: TheraVision software is an image-guided ultrasound ablation system that activates the applicator and can monitor the thermal energy emitted by each transducer. D: MRIT allows for real-time monitoring of thermal distribution, reducing damage to adjacent structures. Scale shows degrees in Celsius.

due to patient motion and near-field heating. ${ }^{23}$ Interstitial HIFU technology can provide the means to tailor more conformal heating patterns and allow for precise margins regardless of tumor shape, location, and proximity to blood vessels. ${ }^{3}$ Furthermore, it allows for the possibility of concurrent biopsy, as well as treatment during the same procedure.

Interstitial HIFU catheters have evolved from initial single-element, noncooled catheters with planar elements to modern multi-elemental, cooled catheters with cylindrical elements. ${ }^{1}$ In 2014, N'Djin et al. conducted a study showing feasibility of spatial heating pattern prediction by using a linear ultrasound transducer in a porcine model. ${ }^{23}$ Our lab currently utilizes Acoustic MedSystem, Inc.'s TheraVision Ultrasound Ablation System and ACOUSTx applicators, which contain multiple, cylindrical, MRIcompatible transducers that afford multidirectionality for precise shaping of the ablative field and allow for treatment of large tumors. This is achieved by independently activating the transducers along the length of the applicator. Finally, the applicator is encased in a Celcon catheter, which allows degassed water to circulate over the transducers, protecting them from thermal effects, couples the ultrasound energy, and increases thermal penetration into the target volume (https://www.accessdata.fda.gov/cdrh_ docs/pdf15/K150019.pdf) (Table 1).

\section{MRI-Guided Robotic Assistance}

Without the ability of MRI to provide real-time feedback, HIFU in the brain at this point would not be possible. To streamline performing stereotaxy in the MRI suite, we have administered HIFU in our swine model with an MRI-compatible robotic assistant that allows for positioning the device at our entry point and for alignment of the trajectory. Kocher's point has been used as our initial entry for proof of concept. Once the alignment is selected, the robotic assistant can then advance the HIFU device to the area being treated from entirely within the bore of the scanner. Robotic movement and imaging may be performed simultaneously, enabling live image-based feedback.

Briefly, the MRgRA and fiducial frame are fixed onto a base platform and placed in the MRI bore, upon which the subject is fixed. The MRgRA has a remote center of motion manipulator that provides for a fixed rotation point around the target with two orthogonal axes, mimicking the arc angles of the stereotactic frame (Fig. 2). ${ }^{16}$ Three degrees of freedom (DOF) enable placement of the tip at 
TABLE 1. Comparison of SRS, LITT, extracorporeal HIFU, and interstitial HIFU

\begin{tabular}{|c|c|c|c|c|}
\hline Feature & SRS & LITT & Extracorporeal HIFU & Interstitial HIFU \\
\hline Technology & $\begin{array}{l}\text { Delivers targeted radiation } \\
\text { using multiple nonparallel } \\
\text { beams. Where beams over- } \\
\text { lap is where the greatest } \\
\text { amount of radiation occurs. }\end{array}$ & $\begin{array}{l}\text { Light absorption causes } \\
\text { the release of thermal } \\
\text { energy to ablate } \\
\text { targeted tissue. }\end{array}$ & $\begin{array}{l}\text { Thermal ablation w/ sequential } \\
\text { coagulation of small overlapping } \\
\text { volumes w/ multiple, individual, } \\
\text { short-time, high-power sonications } \\
\text { delivered outside of the body. }\end{array}$ & $\begin{array}{l}\text { Thermal ablation targeted therapy } \\
\text { that can be delivered intersti- } \\
\text { tially. Applicators are encased to } \\
\text { protect surrounding tissue from } \\
\text { thermal effects. }\end{array}$ \\
\hline Uses & $\begin{array}{l}\text { Gold standard for brain tumor } \\
\text { treatment currently in } \\
\text { conjunction w/ resection \& } \\
\text { chemotherapy. }\end{array}$ & $\begin{array}{l}\text { Currently used as a surgi- } \\
\text { cal option in essential } \\
\text { tremor \& epilepsy. }\end{array}$ & $\begin{array}{l}\text { Useful for very small malignant } \\
\text { lesions. }\end{array}$ & $\begin{array}{l}\text { Tailors more conformal heating } \\
\text { patterns. Allows for precise } \\
\text { margins regardless of tumor } \\
\text { shape, location, \& proximity to } \\
\text { blood vessels. }\end{array}$ \\
\hline Benefits & $\begin{array}{l}\text { Targeted approach for large, } \\
\text { irregularly shaped tumors } \\
\text { near critical anatomical } \\
\text { structures. }\end{array}$ & $\begin{array}{l}\text { Minimally invasive. Re- } \\
\text { duced healing time. }\end{array}$ & Noninvasive. & $\begin{array}{l}\text { Allows for the possibility of concur- } \\
\text { rent biopsy, as well as treatment } \\
\text { during the same procedure. } \\
\text { Offers increased thermal pen- } \\
\text { etration into target volume. }\end{array}$ \\
\hline $\begin{array}{l}\text { Areas of } \\
\text { improve- } \\
\text { ment }\end{array}$ & $\begin{array}{l}\text { No biopsy. Conformal patterns } \\
\text { for all tumor shapes may be } \\
\text { difficult. }\end{array}$ & $\begin{array}{l}\text { May not be used around } \\
\text { blood vessels or large } \\
\text { hemorrhages. Charring } \\
\text { with laser. Invasive. }\end{array}$ & $\begin{array}{l}\text { Treatment may be limited due to } \\
\text { patient motion \& near-field heating. } \\
\text { Treatment can last several hrs. } \\
\text { Cannot be used near the skull. }\end{array}$ & Invasive therapy. \\
\hline
\end{tabular}

the burr hole skull entry point, with the probe at the intended orientation. An additional 2 DOF provide for insertion and rotation of the instrument. The robot is intended to be kinematically similar to a stereotactic frame (Fig. 2). ${ }^{24}$ The robot is registered to the MRI scanner coordinate system with a fiducial frame attached to the bottom of the base platform, composed of 9 tubes filled with MRI-visible, high-contrast fluid and configured in a set of $\mathrm{Z}$ shapes similar to a standard Cosman-Roberts-Wells frame. ${ }^{25}$ Localization of the robot with respect to the imaging system, and thus the animal, was accomplished by using multiple coronal images of the Z-shaped framework. At this point, the pig is moved into the MRI scanner after having undergone burr hole placement and corticotomy in an adjacent sterile room. A set of planning T1-weighted images of the swine is then obtained, with known registration relative to the frame and robot. The neurosurgeon (J.P.) then determines the trajectory and target. After robotic positioning and alignment of the 3 DOF position and 2 DOF orientation, the neurosurgeon introduces a cannula held by the robotic assistant through the corticotomy. The MrgRA then inserts the interstitial HIFU needle through the cannula and images are obtained to confirm placement prior to ablation. Therapy is then guided through MRIT.

The MRI-compatible HIFU probes were designed using multi-element tubular piezoelectric transducers mounted on a hollow polyimide tube. All piezoelectric transducers had $360^{\circ}$ directionality and were either 10
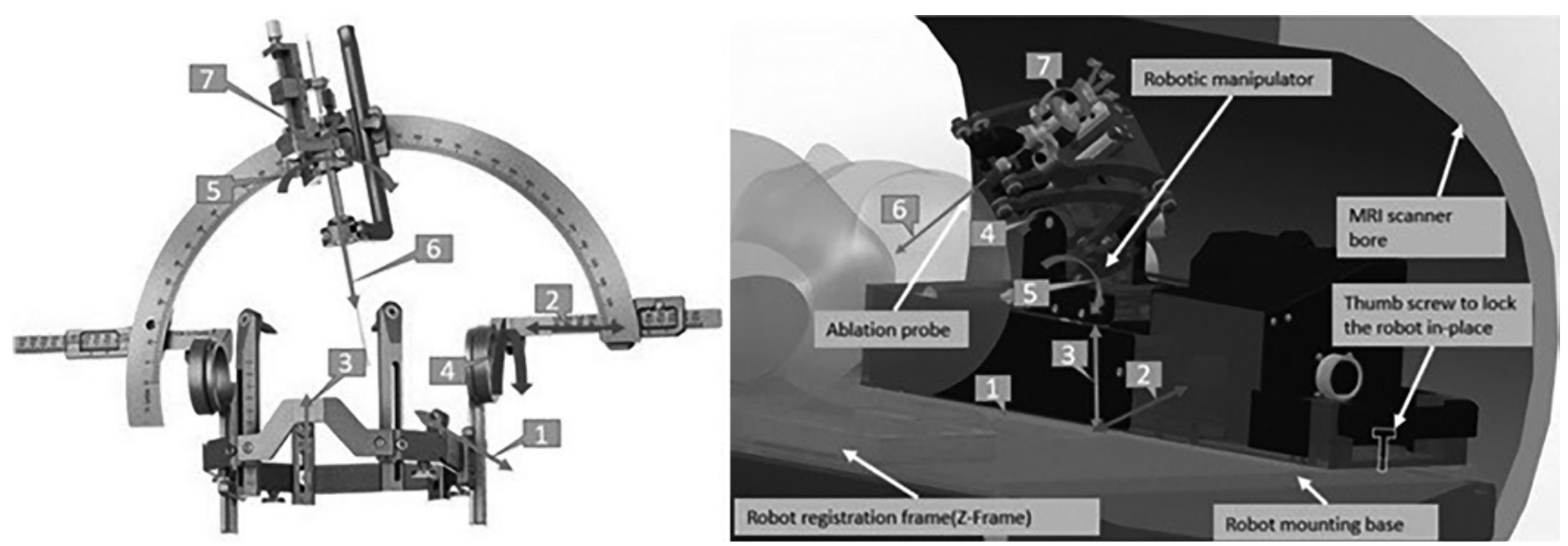

FIG. 2. The Leksell Stereotactic System from Elekta (left) and the robotic manipulator (right) showing motion capabilities. The robotic manipulator is slid into the guiding rails and locked in place with a thumb screw. The robot registration frame is attached to the robot base and does not need to be mounted/unmounted for each procedure. 


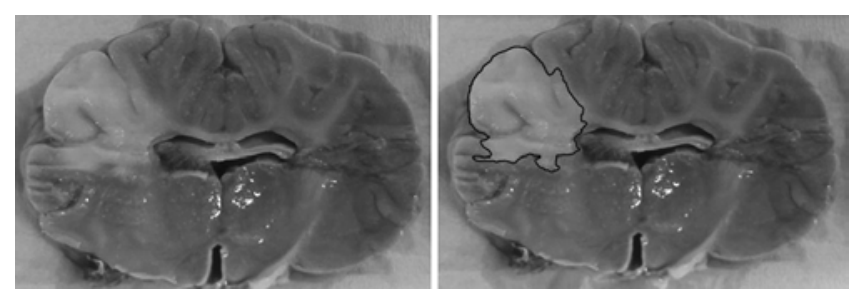

FIG. 3. Triphenyltetrazolium chloride-stained coronal brain slices. The lighter area depicts infarct, and the darker area depicts viable tissue. Area of ablation outlined in the image on the right.

$\mathrm{mm}(\mathrm{n}=7)$ or $7 \mathrm{~mm}(\mathrm{n}=3)$ long with a 1.5 -mm outer diameter. Each transducer had a thermocouple sensor capable of monitoring temperature in real time. A 13-gauge implant catheter was used to insert the HIFU probe, and degassed water circulated through the catheter to prevent the transducer from overheating. HIFU applicators were activated using the FDA-approved TheraVision software system. Our preliminary data determined that energy is delivered at a 4-W acoustic output power over 180 seconds to obtain a $2-\mathrm{cm}^{3}$ ablation zone (Fig. 3). Work using directional ablative probes is ongoing.

\section{Conclusions}

Interstitial HIFU therapy for intracranial tumors utilizes ultrasound technology as a minimally invasive method of tumor ablation. With the concept of a catheter delivery system as the treatment delivery modality, the natural barrier of the calvaria is circumvented. Interstitial HIFU also enables diagnostic capabilities through the cannula and precise conformal tumor ablation. The application of an automated system via a robot improves workflow and efficiency of the delivery system. This treatment system has been shown to work in animal models as a proof of concept.

\section{Acknowledgments}

Dr. Pilitsis received grant funding from NIH (1R01CA166379).

\section{References}

1. Canney MS, Chavrier F, Tsysar S, Chapelon JY, Lafon C, Carpentier A: A multi-element interstitial ultrasound applicator for the thermal therapy of brain tumors. J Acoust Soc Am 134:1647-1655, 2013

2. Chen X, Diederich CJ, Wootton JH, Pouliot J, Hsu IC: Optimisation-based thermal treatment planning for catheterbased ultrasound hyperthermia. Int J Hyperthermia 26:3955,2010

3. Christian E, Yu C, Apuzzo MLJ: Focused ultrasound: relevant history and prospects for the addition of mechanical energy to the neurosurgical armamentarium. World Neurosurg 82:354-365, 2014

4. Cohen-Inbar O, Melmer P, Lee CC, Xu Z, Schlesinger D, Sheehan JP: Leukoencephalopathy in long term brain metastases survivors treated with radiosurgery. J Neurooncol 126:289-298, 2016

5. Coluccia D, Fandino J, Schwyzer L, O’Gorman R, Remonda L, Anon J, et al: First noninvasive thermal ablation of a brain tumor with MR-guided focused ultrasound. J Ther Ultrasound 2:17, 2014
6. Diederich CJ, Stafford RJ, Nau WH, Burdette EC, Price RE, Hazle JD: Transurethral ultrasound applicators with directional heating patterns for prostate thermal therapy: in vivo evaluation using magnetic resonance thermometry. Med Phys 31:405-413, 2004

7. Elias WJ, Huss D, Voss T, Loomba J, Khaled M, Zadicario E, et al: A pilot study of focused ultrasound thalamotomy for essential tremor. N Engl J Med 369:640-648, 2013

8. Hatiboglu MA, Wildrick DM, Sawaya R: The role of surgical resection in patients with brain metastases. Ecancermedicalscience 7:308, 2013

9. Hynynen K, McDannold N, Clement G, Jolesz FA, Zadicario E, Killiany R, et al: Pre-clinical testing of a phased array ultrasound system for MRI-guided noninvasive surgery of the brain - a primate study. Eur J Radiol 59:149-156, 2006

10. Insightec: Insightec neurosurgery. Clinical indications. Insightec. (https://www.insightec.com/us/clinical/ neurosurgery) [Accessed December 5, 2017]

11. Jagannathan J, Sanghvi NT, Crum LA, Yen CP, Medel R, Dumont AS, et al: High-intensity focused ultrasound surgery of the brain: part 1-a historical perspective with modern applications. Neurosurgery 64:201-211, 2009

12. Jang HJ, Lee JY, Lee DH, Kim WH, Hwang JH: Current and future clinical applications of high-intensity focused ultrasound (HIFU) for pancreatic cancer. Gut Liver 4 (Suppl 1):S57-S61, 2010

13. Kang JY, Wu C, Tracy J, Lorenzo M, Evans J, Nei M, et al: Laser interstitial thermal therapy for medically intractable mesial temporal lobe epilepsy. Epilepsia 57:325-334, 2016

14. Keane MG, Bramis K, Pereira SP, Fusai GK: Systematic review of novel ablative methods in locally advanced pancreatic cancer. World J Gastroenterol 20:2267-2278, 2014

15. Kennedy JE, Ter Haar GR, Cranston D: High intensity focused ultrasound: surgery of the future? Br J Radiol 76:590-599, 2003

16. Li G, Su H, Cole GA, Shang W, Harrington K, Camilo A, et al: Robotic system for MRI-guided stereotactic neurosurgery. IEEE Trans Biomed Eng 62:1077-1088, 2015

17. Maloney E, Hwang JH: Emerging HIFU applications in cancer therapy. Int J Hyperthermia 31:302-309, 2015

18. McDannold N, Clement GT, Black P, Jolesz F, Hynynen K: Transcranial magnetic resonance imaging- guided focused ultrasound surgery of brain tumors: initial findings in 3 patients. Neurosurgery 66:323-332, 2010

19. Mearini L, Porena M: Transrectal high-intensity focused ultrasound for the treatment of prostate cancer: past, present, and future. Indian J Urol 26:4-11, 2010

20. Medvid R, Ruiz A, Komotar RJ, Jagid JR, Ivan ME, Quencer RM, et al: Current applications of MRI-guided laser interstitial thermal therapy in the treatment of brain neoplasms and epilepsy: a radiologic and neurosurgical overview. AJNR Am J Neuroradiol 36:1998-2006, 2015

21. Missios S, Bekelis K, Barnett GH: Renaissance of laser interstitial thermal ablation. Neurosurg Focus 38(3):E13, 2015

22. Mut M: Surgical treatment of brain metastasis: a review. Clin Neurol Neurosurg 114:1-8, 2012

23. N'Djin WA, Burtnyk M, Lipsman N, Bronskill M, Kucharczyk W, Schwartz ML, et al: Active MR-temperature feedback control of dynamic interstitial ultrasound therapy in brain: in vivo experiments and modeling in native and coagulated tissues. Med Phys 41:093301, 2014

24. Nycz CJ, Gondokaryono R, Carvalho P, Patel N, Wartenberg M, Pilitsis JG, et al: Mechanical validation of an MRI compatible stereotactic neurosurgery robot in preparation for pre-clinical trials, presented at the IEEE/RSJ International Conference on Intelligent Robots and Systems - IROS 2017. (Abstract) (https://ras.papercept.net/conferences/ 
conferences/IROS17/program/IROS17_ContentListWeb_2. html\#moct5_03) [Accessed December 5, 2017]

25. Pell MF, Thomas DG: The initial experience with the Cosman-Roberts-Wells stereotactic system. Br J Neurosurg 5:123-128, 1991

26. Sofuni A, Asai Y, Sano T, Mitsuru F, Tsuchiya T, Tsuji S, et al: High-intensity focused ultrasound (HIFU) therapy for unresectable pancreatic cancer. Gastroenterology 152 (Suppl 1):S498, 2017

27. Von Hoff DD, Ervin T, Arena FP, Chiorean EG, Infante J, Moore M, et al: Increased survival in pancreatic cancer with nab-paclitaxel plus gemcitabine. N Engl J Med 369:16911703, 2013

28. Yaeger KA, Nair MN: Surgery for brain metastases. Surg Neurol Int 4 (Suppl 4):S203-S208, 2013

\section{Disclosures}

Dr. Pilitsis is a consultant for Medtronic, Centauri, Boston Scien- tific, and Abbott; receives grant support from Medtronic, Boston Scientific, Abbott, Nevro, Jazz Pharmaceuticals, and GE Global Research; is a medical advisor for Centauri and Karuna, where she has stock equity; and is on the speakers' bureau at Boston Scientific and Jazz Pharmaceuticals. Mr. Burdette is the CEO of Acoustic MedSystems, Inc. Mr. Ghoshal is an employee of Acoustic MedSystems, Inc. Mr. Fischer is a consultant for Centauri.

\section{Author Contributions}

Conception and design: Pilitsis, MacDonell, Ghoshal, Fischer, Burdette. Acquisition of data: Burdette. Analysis and interpretation of data: Pilitsis. Drafting the article: all authors. Critically revising the article: Pilitsis, MacDonell, Ghoshal, Fischer, Burdette. Reviewed submitted version of manuscript: Pilitsis, MacDonell. Study supervision: Pilitsis.

\section{Correspondence}

Julie G. Pilitsis: Albany Medical Center, Albany, NY.pilitsj@ mail.amc.edu. 